\title{
A recurrent and transesophageal echocardiography-associated outbreak of extended-spectrum $\beta$-lactamase-producing Enterobacter cloacae complex in cardiac surgery patients
}

Tom Van Maerken ${ }^{1,2}$, Els De Brabandere ${ }^{3}$, Audrey Noël ${ }^{4}$, Liselotte Coorevits ${ }^{5,6}$, Pascal De Waegemaeker ${ }^{3}$, Raina Ablorh ${ }^{3}$, Stefaan Bouchez ${ }^{7}$, Ingrid Herck ${ }^{8}$, Harlinde Peperstraete ${ }^{8}$, Pierre Bogaerts ${ }^{4}$, Bruno Verhasselt ${ }^{5,6}$, Youri Glupczynski ${ }^{4}$, Jerina Boelens ${ }^{3,5,6}$ and Isabel Leroux-Roels ${ }^{3,5,6^{*}}$ (D)

\begin{abstract}
Background: We report a recurrent outbreak of postoperative infections with extended-spectrum $\beta$-lactamase (ESBL)-producing E. cloacae complex in cardiac surgery patients, describe the outbreak investigation and highlight the infection control measures.

Methods: Cases were defined as cardiac surgery patients in Ghent University Hospital who were not known preoperatively to carry ESBL-producing E. cloacae complex and who postoperatively had a positive culture for this multiresistant organism between May 2017 and January 2018. An epidemiological investigation, including a casecontrol study, and environmental investigation were conducted to identify the source of the outbreak. Clonal relatedness of ESBL-producing E. cloacae complex isolates collected from case patients was assessed using wholegenome sequencing-based studies.
\end{abstract}

Results: Three separate outbreak episodes occurred over the course of 9 months. A total of 8,4 and 6 patients met the case definition, respectively. All but one patients developed a clinical infection with ESBL-producing E. cloacae complex, most typically postoperative pneumonia. Overall mortality was 22\% (4/18). Environmental cultures were negative, but epidemiological investigation pointed to transesophageal echocardiography (TEE) as the outbreak source. Of note, four TEE probes showed a similar pattern of damage, which very likely impeded adequate disinfection. The first and second outbreak episode were caused by the same clone, whereas a different strain was responsible for the third episode.

Conclusions: Health professionals caring for cardiac surgery patients and infection control specialists should be aware of TEE as possible infection source. Caution must be exercised to prevent and detect damage of TEE probes.

Keywords: Outbreak, Cardiac surgery, Enterobacter cloacae complex, Extended-spectrum $\beta$-lactamase, Transesophageal echocardiography

\footnotetext{
* Correspondence: Isabel.LerouxRoels@uzgent.be

${ }^{3}$ Department of Infection Control, Ghent University Hospital, Ghent, Belgium

${ }^{5}$ Department of Laboratory Medicine, Ghent University Hospital, Ghent,

Belgium

Full list of author information is available at the end of the article
}

(c) The Author(s). 2019 Open Access This article is distributed under the terms of the Creative Commons Attribution 4.0 International License (http://creativecommons.org/licenses/by/4.0/), which permits unrestricted use, distribution, and reproduction in any medium, provided you give appropriate credit to the original author(s) and the source, provide a link to the Creative Commons license, and indicate if changes were made. The Creative Commons Public Domain Dedication waiver (http://creativecommons.org/publicdomain/zero/1.0/) applies to the data made available in this article, unless otherwise stated. 


\section{Background}

Members of the Enterobacter cloacae complex are part of the commensal intestinal flora in humans and can act as opportunistic pathogens to cause serious nosocomial infections. These facultative anaerobic Gram-negative bacilli are intrinsically resistant to ampicillin, amoxicillin, amoxicillin-clavulanic acid, first-generation cephalosporins and cefoxitin due to the production of constitutive AmpC $\beta$-lactamase [1]. Plasmid-mediated $\beta$-lactam resistance is increasingly reported in E. cloacae complex strains worldwide. The most recent estimates in Belgian acute care hospitals indicate that 12.4 and $1.6 \%$ of all E. cloacae complex strains are producing extended-spectrum $\beta$-lactamases (ESBLs) and carbapenemases, respectively [2].

We have been confronted with an increased incidence of ESBL-producing E. cloacae complex infections in cardiac surgery patients in Ghent University Hospital from May 2017 onwards. Epidemiological investigation pointed to transesophageal echocardiography (TEE) as the source of the outbreak. Despite initially successful institution of infection control measures, the outbreak recurred twice over the course of 9 months. We report here the different outbreak episodes and shed light on a number of critical aspects that should be taken into account to prevent and control similar epidemics in other hospitals.

\section{Methods}

\section{Clinical setting}

Ghent University Hospital is a 1062-bed tertiary care hospital in East Flanders, Belgium. Approximately 1000 cardiac operations on adult and pediatric patients are performed annually by six cardiac surgeons in two designated cardiac operating rooms. Patients are admitted postoperatively to a 10 -bed cardiac surgery intensive care unit (CSICU), where they are treated until sufficiently recovered to be transferred to a 28-bed cardiac surgery ward. The hospital has an infection control team composed of two physicians, three nurses and three administrative staff members.

\section{Case definition}

Cases were defined as patients who underwent cardiac surgery in Ghent University Hospital between May 2017 and January 2018 and who subsequently developed colonization or infection with ESBL-producing E. cloacae complex as demonstrated by a positive culture from any site. Patients known preoperatively to carry ESBL-producing E. cloacae complex were excluded from the case definition. Systematic preoperative screening of cardiac surgery patients for multiresistant Gram-negative bacteria was installed end of June 2017, implying that the preoperative microbiological status is not known for all cases in the first 1.5 months of the outbreak. An outbreak episode was defined as at least two cases linked by a temporal and epidemiological chain of transmission.

\section{Epidemiological investigation}

Several outbreak meetings were held between the hospital infection control team and cardiac surgeons, anesthesiologists, intensivists, cardiologists, operating room nurses and intensive care nurses to identify the source of the outbreak and to discuss and implement infection control measures. Medical records of all cases were reviewed to uncover common factors. The care pathway of cardiac surgery patients was evaluated by the infection control team, including assessment of preoperative care, direct observation of cardiac operations and hand hygiene practices, inspection of wound and airway care and other care-related activities at CSICU, assessment of antibiotic prescribing, analysis of reprocessing of equipment and evaluation of cleaning and disinfection procedures. Special emphasis was given to the use and disinfection of TEE probes, as TEE examinations are typically performed in cardiac surgery patients and as most cases presented with ESBL-producing E. cloacae complex in respiratory samples. Preoperative screening of rectal and throat swabs and weekly postoperative screening of rectal swabs for multiresistant Gram-negative bacteria were carried out in all cardiac surgery patients after recognition of the outbreak at the end of June 2017.

Baseline incidence, attack rate and post-outbreak incidence of ESBL-producing E. cloacae complex at CSICU were quantified in the period from January 2017 to June 2018 by dividing the monthly number of new CSICU patients with an ESBL-producing E. cloacae complex isolate from any site, with 'new' being defined as not previously known at any ward or intensive care unit (ICU) as being colonized or infected, by one hundredth of the monthly number of admissions at CSICU. Similar incidence rates per 100 admissions were calculated for the cardiac intensive care unit (CICU), the medical intensive care unit (MICU), the non-cardiac surgical intensive care unit (SICU) and the entire hospital excluding CSICU.

A retrospective case-control study was performed on the patients from the first outbreak episode. As the number of cases was limited, two controls were included per case in order to increase statistical power. The selected controls were those two cardiac surgery patients who did not show ESBL-producing E. cloacae complex in any of their samples during the entire hospital stay and who had their operation as close as possible to the cardiac surgery of the case patient. The following preoperative, intraoperative and postoperative characteristics were retrieved from the medical records and compared between cases and controls: age, gender, body mass index (BMI), smoking habit, medical history, preoperative length of stay, preoperative ICUs or wards, 
preoperative medication, preoperative American Society of Anesthesiologists (ASA) score, type of cardiac surgery, emergency setting of the operation, operating room, surgeons, anesthesiologists, surgical antibiotic prophylaxis, sternotomy, extracorporeal circulation (ECC), duration of surgery, duration of ECC, intraoperative TEE, postoperative TEE, need for revision, beds occupied at CSICU, length of stay at CSICU, postoperative length of stay, total length of stay and outcome.

\section{Environmental investigation}

Environmental surveillance samples were collected by the hospital infection control team at several time points during the outbreak. Sampled materials included the different TEE probes used in cardiac surgery patients, keyboards of the ultrasound machines, protective foam covers for the TEE probe tips, a storage case for the TEE probe at CSICU, ultrasound transmission gel, caps of the ultrasound gel tubes, warm water mattresses in the operating rooms, water from extracorporeal membrane oxygenation systems and pillows for neonates at CSICU.

\section{Microbiological methods}

Clinical samples were processed and cultured in the microbiology laboratory using standard diagnostic protocols. Rectal and throat screening swab specimens were grown on selective chromogenic agar plates (chromID ESBL; bioMérieux, Marcy l'Etoile, France). Environmental surveillance samples were cultured using direct plating and enriched broth techniques. Suspicious colonies were identified by matrix-assisted laser desorption/ionization time-of-flight mass spectrometry (MALDI-TOF MS) on a Microflex LT instrument (Bruker Daltonics, Bremen, Germany). Antibiotic susceptibility testing of E. cloacae complex isolates was performed on an Adagio automated system (Bio-Rad, Hercules, CA, USA) using the disk diffusion method and interpreted according to European Committee on Antimicrobial Susceptibility Testing (EUCAST) breakpoints. Phenotypic identification of ESBL production was based on double disk synergy testing using cefotaxime, ceftazidime, amoxicillin-clavulanic acid and piperacillin-tazobactam. A combination disk diffusion test using cefepime and cefepime-clavulanic acid was performed to confirm ESBL production during the third outbreak episode.

\section{Molecular methods}

Molecular characterization of ESBL-producing E. cloacae complex isolates was performed by whole-genome sequencing. Genomic DNA was extracted from the available outbreak isolates and from three unrelated ESBL-producing E. cloacae complex isolates that had been cultured from rectal screening swabs of non-cardiac surgery patients hospitalized at the wards of geriatry, abdominal surgery and pneumology in October and November 2017. DNA libraries were prepared using the Nextera XT DNA Library Preparation Kit (Illumina, San Diego, CA, USA) and sequenced as 300-bp paired-end reads on a MiSeq system (Illumina). Sequencing reads were assembled using CLC Genomics Workbench version 11.0 (Qiagen, Hilden, Germany). Assembled contigs were uploaded to ResFinder version 3.0 to detect the presence of acquired antimicrobial resistance genes [3, 4]. Multilocus sequence typing (MLST) of the isolates was performed by submitting the contigs to the MLST version 1.8 web service $[5,6]$.

\section{Statistical analysis}

Data of the case-control study were processed and analyzed using SPSS Statistics version 25 (IBM, Armonk, NY, USA). Differences in the distribution of categorical variables between cases and controls were assessed by computing odds ratios (ORs) and corresponding 95\% confidence intervals (CIs) and by performing Fisher's exact tests. A Haldane's correction, consisting of addition of 0.5 to all four cells of the contingency table, was applied in the OR calculation if unadjusted values resulted in division by zero. Differences in the distribution of continuous variables between cases and controls were analyzed by Mann-Whitney $U$ tests. All statistical tests were twosided and were considered significant at $P<.05$.

\section{Results}

\section{First outbreak episode}

A cluster of postoperative infections with ESBL-producing E. cloacae complex in cardiac surgery patients was signalled to the infection control team of Ghent University Hospital in June 2017. Analysis of the monthly incidence rates of patients with a positive culture for ESBL-producing E. cloacae complex showed an epidemic increase at CSICU that had started in May 2017 (Fig. 1). Eight cases were detected between May and July 2017. Table 1 shows the demographic and clinical characteristics of the cases, the treatment given and the outcome of the hospital stay. The case definition included both postoperatively colonized and clinically infected cardiac surgery patients, but all cases of the first outbreak episode had clinical signs of infection and received treatment with piperacillin-tazobactam (TZP) or meropenem (MEM). Two of these case patients had a fatal outcome, which was not considered directly related to the postoperative infection by the physician in charge.

The presence of ESBL-producing E. cloacae complex in respiratory samples in all but one cases and the development of postoperative pneumonia in most cases led us rapidly to consider airway-related procedures as possible source of the outbreak. A major suspected culprit was the performance of TEE examinations in cardiac surgery patients. Typically a TEE probe is inserted through 


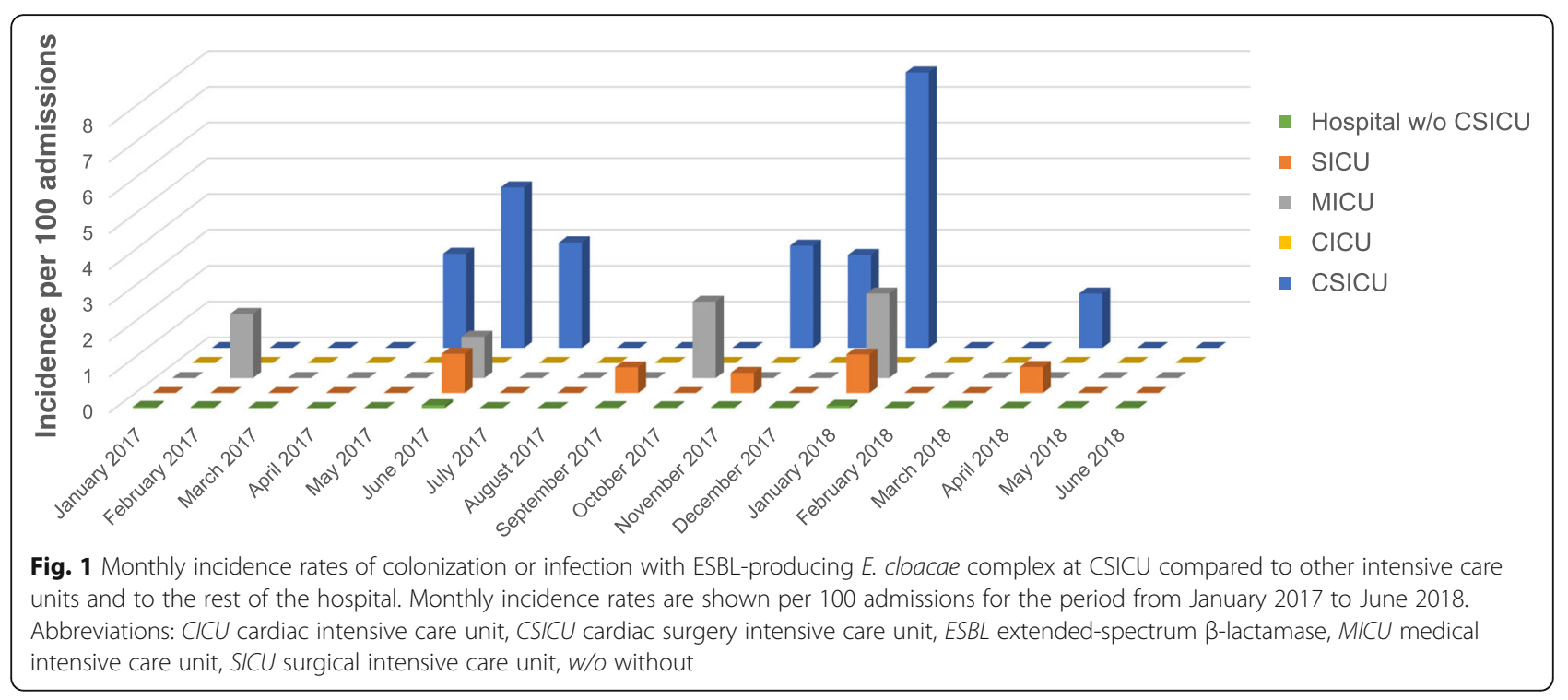

the oropharynx into the esophagus after anesthesia induction and placed in a retrocardiac position for the entire duration of the operation to visualize the structure and function of the heart. Additional TEE examinations may be performed in the postoperative period. Samples were taken from the TEE probes of the cardiac operating rooms and CSICU the end of June 2017, after the first six cases had occurred, but all cultures were negative. Inspection of the TEE probe of operating room A, where five of these six case patients had been operated, showed clear damage to the silicone bead around the transducer lens and the polyethylene film covering the lens (Fig. 2a). It was decided to remove the TEE probe from service. Ten days later two new cases occurred, again with positive respiratory samples. Inspection of the TEE probe of CSICU, which had been used to perform postoperative TEE examinations in both patients, demonstrated a similar pattern of damage (Fig. 2b). Analysis of the incidence rates of ESBL-producing E. cloacae complex at other ICUs showed a minor peak at SICU and MICU in June 2017 (two and one new patients, respectively; Fig. 1). Both infected non-cardiac patients at SICU had positive respiratory samples and turned out to have had a TEE examination shortly beforehand, which was very likely performed using the TEE probe of CSICU. This probe was removed from service mid July 2017, after which the first outbreak episode stopped. Figure 3 shows a timeline of cases and key interventions performed to control the outbreak. The entire set of infection control measures is depicted in Additional file 1: Table S1.

A case-control study was performed to identify risk factors and outcome characteristics associated with the development of ESBL-producing E. cloacae complex infection following cardiac surgery (Table 2). Compared to 16 control patients, the 8 cases were more likely to have a longer duration of surgery (median, $275 \mathrm{~min}$ vs 197 min; $P=.011$ ) and to have traceable TEE examinations in the postoperative period $(\mathrm{OR}=15.40$ [95\% CI, 1.47160.97]; $P=.027$ ). These findings are consistent with the hypothesis of intraoperative and postoperative TEE examinations as source of the outbreak. Cases were more likely than controls to have a preoperative ASA score of $5(\mathrm{OR}=$ 17.00 [95\% CI, 1.59-181.36]; $P=.007$ ), an emergency operation $(\mathrm{OR}=17.00$ [95\% CI, 1.59-181.36]; $P=.007)$ and a postoperative need for urgent revision due to a non-infectious complication $(\mathrm{OR}=25.50$ [95\% CI, 2.36-275.74]; $P=.001)$. Bed position E at CSICU was more often occupied by cases than controls (OR $=15.00$ [95\% CI, 1.29174.39]; $P=.028$ ). Cases also had significantly longer length of stay at CSICU compared to controls (median, 15 days vs 3 days; $P=.006$ ), longer postoperative length of stay (median, 30 days vs 10 days; $P<.001$ ) and longer total length of stay (median, 34 days vs 12 days; $P=.001$ ).

\section{Second outbreak episode}

Four months passed without any new cardiac surgery patient having cultures positive for ESBL-producing E. cloacae complex. The outbreak, however, unexpectedly recurred mid November 2017, with four new cases being identified over the course of 1 month (Fig. 1). All cases were symptomatic and three of them had an acute respiratory infection with ESBL-producing E. cloacae complex in the postoperative period (Table 1). These three cases were infants, whereas all patients of the first outbreak episode were adults, and one infant did not have traceable TEE examinations. This caused uncertainty whether these new cases were related to the first outbreak episode and suggested a multifactorial mode of transmission. All cases recovered after antibiotic treatment and could be discharged from the hospital. 
Table 1 Demographic characteristics, clinical features, treatment and outcome of case patients

\begin{tabular}{|c|c|c|c|c|c|c|c|c|c|}
\hline $\begin{array}{l}\text { Case } \\
\text { No. }{ }^{a}\end{array}$ & $\begin{array}{l}\text { Age } \\
\text { (yrs) }\end{array}$ & Sex & Type of surgery & $\begin{array}{l}\text { Need for } \\
\text { revision }{ }^{b}\end{array}$ & Type of infection & $\begin{array}{l}\text { Postoperative } \\
\text { days to infection }\end{array}$ & Sample types ${ }^{d}$ & Treatment $^{\mathrm{e}}$ & Outcome ${ }^{f}$ \\
\hline 1 & 42 & M & LVAD implantation & No & Pneumonia & 28 & $\begin{array}{l}\text { Sputum, oropharynx, } \\
\text { chest tube insertion } \\
\text { site, stool, sacral } \\
\text { decubitus ulcer }\end{array}$ & TZP & Discharge \\
\hline 2 & 55 & M & $\begin{array}{l}\text { Aortic dissection } \\
\text { repair }\end{array}$ & Yes & Pneumonia & $2(1)$ & $\begin{array}{l}\text { Endotracheal } \\
\text { aspirate, sputum, } \\
\text { oropharynx, stool }\end{array}$ & TZP, MEM & Discharge \\
\hline 3 & 75 & F & $\begin{array}{l}\text { Aortic valve } \\
\text { replacement }\end{array}$ & Yes & Pneumonia & $2(2)$ & $\begin{array}{l}\text { Sputum, } \\
\text { endotracheal } \\
\text { aspirate, stool }\end{array}$ & MEM & Discharge \\
\hline 4 & 53 & M & $\begin{array}{l}\text { LVAD implantation, } \\
\text { tricuspid annuloplasty }\end{array}$ & $\begin{array}{l}\text { Yes } \\
\text { (twice) }\end{array}$ & CRBSI & $12(7 ; 6)$ & $\begin{array}{l}\text { Blood, CVC tip, } \\
\text { oropharynx, stool }\end{array}$ & $\begin{array}{l}\text { TZP, MEM, CVC } \\
\text { removal }\end{array}$ & Death \\
\hline 5 & 80 & M & CABG & No & $\begin{array}{l}\text { Sternal wound } \\
\text { infection, } \\
\text { mediastinitis }\end{array}$ & 5 & $\begin{array}{l}\text { Sternal wound } \\
\text { fluid, sternal } \\
\text { and mediastinal } \\
\text { debridement } \\
\text { samples }\end{array}$ & $\begin{array}{l}\text { MEM, sternal } \\
\text { and mediastinal } \\
\text { debridement }\end{array}$ & Discharge $^{g}$ \\
\hline 6 & 72 & F & $\begin{array}{l}\text { Mitral valve } \\
\text { replacement, } \\
\text { tricuspid } \\
\text { annuloplasty, } \\
\text { maze procedure, } \\
\text { PFO closure, } \\
\text { LAA exclusion }\end{array}$ & No & Pneumonia & 3 & $\begin{array}{l}\text { Endotracheal } \\
\text { aspirate, } \\
\text { oropharynx, } \\
\text { BAL fluid, stool }\end{array}$ & TZP & Discharge \\
\hline 7 & 78 & $\mathrm{~F}$ & $\begin{array}{l}\text { CABG, aortic valve } \\
\text { replacement }\end{array}$ & No & Pneumonia, CRBSI & 3 & $\begin{array}{l}\text { Endotracheal } \\
\text { aspirate, blood, } \\
\text { CVC tip, AC } \\
\text { insertion site, } \\
\text { stool }\end{array}$ & $\begin{array}{l}\text { TZP, MEM, CVC } \\
\text { removal }\end{array}$ & Death \\
\hline
\end{tabular}

\begin{tabular}{|c|c|c|c|c|c|c|c|c|c|}
\hline 8 & 86 & $F$ & $\begin{array}{l}\text { Aortic dissection } \\
\text { repair }\end{array}$ & Yes & Pneumonia & $2(1)$ & $\begin{array}{l}\text { Oropharynx, } \\
\text { sputum, stool }\end{array}$ & MEM & Discharge \\
\hline 9 & $<.1$ & $\mathrm{~F}$ & $\begin{array}{l}\text { Aortic coarctation } \\
\text { repair, pulmonary } \\
\text { artery banding }\end{array}$ & Yes & $\begin{array}{l}\text { Tracheo- } \\
\text { bronchitis }\end{array}$ & $14(14)$ & $\begin{array}{l}\text { Oropharynx, } \\
\text { endotracheal } \\
\text { aspirate }\end{array}$ & TZP & Discharge \\
\hline 10 & .3 & M & $\begin{array}{l}\text { ASD closure, mitral } \\
\text { valvuloplasty }\end{array}$ & No & Pneumonia & 4 & $\begin{array}{l}\text { Oropharynx, } \\
\text { endotracheal } \\
\text { aspirate, stool, } \\
\text { urine }\end{array}$ & TZP & Discharge \\
\hline 11 & 33 & M & Heart transplantation & No & $\begin{array}{l}\text { Inguinal wound } \\
\text { infection }\end{array}$ & 41 & $\begin{array}{l}\text { Stool, inguinal } \\
\text { wound fluid }\end{array}$ & $\begin{array}{l}\text { Local wound } \\
\text { care }\end{array}$ & Discharge \\
\hline 12 & $<.1$ & M & $\begin{array}{l}\text { Blalock-Taussig } \\
\text { shunt placement }\end{array}$ & No & Pneumonia & 7 & Oropharynx & TZP, MEM & Discharge \\
\hline 13 & 83 & $\mathrm{~F}$ & $\begin{array}{l}\text { Mitral valve } \\
\text { replacement }\end{array}$ & Yes & $\begin{array}{l}\text { Pneumonia, } \\
\text { sepsis }\end{array}$ & $2(1)$ & $\begin{array}{l}\text { Oropharynx, } \\
\text { endotracheal } \\
\text { aspirate, blood, } \\
\text { stool }\end{array}$ & MEM & Death \\
\hline 14 & 60 & M & $\begin{array}{l}\text { CABG, mitral } \\
\text { annuloplasty }\end{array}$ & No & Colonization ${ }^{i}$ & - & $\begin{array}{l}\text { Oropharynx, } \\
\text { endotracheal } \\
\text { aspirate }\end{array}$ & - & Death \\
\hline 15 & 46 & $\mathrm{~F}$ & $\begin{array}{l}\text { Bilateral pulmonary } \\
\text { embolectomy }\end{array}$ & Yes & Pneumonia, UTI & $3(2)$ & $\begin{array}{l}\text { Oropharynx, } \\
\text { endotracheal } \\
\text { aspirate, stool, } \\
\text { urine }\end{array}$ & $\begin{array}{l}\text { TZP, MEM, } \\
\text { nitrofurantoin }\end{array}$ & Discharge \\
\hline 16 & 62 & F & $\begin{array}{l}\text { Aortic valve } \\
\text { replacement }\end{array}$ & No & $\begin{array}{l}\text { Infectious } \\
\text { exacerbation }\end{array}$ & 2 & Sputum, stool & MEM & Discharge \\
\hline
\end{tabular}


Table 1 Demographic characteristics, clinical features, treatment and outcome of case patients (Continued)

\begin{tabular}{|c|c|c|c|c|c|c|c|c|c|}
\hline $\begin{array}{l}\text { Case } \\
\text { No. }{ }^{a}\end{array}$ & $\begin{array}{l}\text { Age } \\
\text { (yrs) }\end{array}$ & Sex & Type of surgery & $\begin{array}{l}\text { Need for } \\
\text { revision }\end{array}$ & Type of infection & $\begin{array}{l}\text { Postoperative } \\
\text { days to infection }\end{array}$ & Sample types $^{d}$ & Treatment $^{\mathrm{e}}$ & Outcome $e^{f}$ \\
\hline & & & & & of COPD & & & & \\
\hline 17 & 64 & M & $\begin{array}{l}\text { Aortic valve } \\
\text { replacement, } \\
\text { mitral annuloplasty }\end{array}$ & No & $\begin{array}{l}\text { Pneumonia, } \\
\text { sepsis, sternal } \\
\text { wound infection }\end{array}$ & 1 & $\begin{array}{l}\text { Oropharynx, blood, } \\
\text { sternal wound fluid }\end{array}$ & $\begin{array}{l}\text { MEM, moxifloxacin, } \\
\text { local wound care }\end{array}$ & Discharge \\
\hline 18 & 75 & M & $\begin{array}{l}\text { Aortic valve } \\
\text { bioprosthesis } \\
\text { replacement, } \\
\text { ascending aorta } \\
\text { replacement }\end{array}$ & Yes & Pneumonia & $16(16)^{1}$ & Oropharynx, stool & MEM & Discharge \\
\hline
\end{tabular}

Abbreviations: $A C$ arterial catheter, $A S D$ atrial septal defect, $B A L$ bronchoalveolar lavage, $C A B G$ coronary artery bypass grafting, $C O P D$ chronic obstructive pulmonary disease, CRBSI catheter-related bloodstream infection, CVC central venous catheter, ESBL extended-spectrum $\beta$-lactamase, $L A A$ left atrial appendage, LVAD left ventricular assist device, MEM meropenem, PFO patent foramen ovale, TZP piperacillin-tazobactam, UTI urinary tract infection

${ }^{a}$ Cases are numbered in chronological order of occurrence. Dashed lines separate the different outbreak episodes

${ }^{b}$ Postoperative need for urgent reoperation because of bleeding with imminent or manifest pericardial tamponade or because of severe ventricular dysfunction ${ }^{c}$ Number of days between cardiac surgery and collection of the first clinical sample positive for ESBL-producing E. cloacae complex. In case of cardiac surgery followed by revision operation(s), values between brackets indicate days between revision operation and infection

${ }^{\mathrm{d}}$ All types of clinical and screening specimens from which ESBL-producing E. cloacae complex was isolated

eWhen both TZP and MEM are listed, TZP was given first and was later replaced by MEM because of antimicrobial susceptibility testing results or treatment failure ${ }^{f}$ Outcome of the hospital stay. Deaths reflect overall mortality (see text for details on attributable mortality)

${ }^{9}$ Case \#5 had to be readmitted after discharge because of relapse of the sternal and mediastinal infection. Retreatment consisted of operative interventions and a prolonged course of high-dose MEM followed by a course of oral trimethoprim-sulfamethoxazole. Full recovery was achieved at the end of the second admission ${ }^{h}$ Case \#11 developed postoperative pneumonia caused by an E. cloacae complex strain that did not produce ESBL according to double disk synergy testing. An inguinal wound infection following percutaneous femoral vein catheterization occurred later in the postoperative period. An ESBL-producing E. cloacae complex strain was cultured from rectal swabs and inguinal wound fluid on postoperative day 19 and day 41, respectively

'Case \#14 died from low cardiac output and peripheral arterial disease on the third postoperative day, a few hours after the collection of two respiratory samples that turned out to be positive for ESBL-producing E. cloacae complex. The available time for developing an overt infection was limited in this patient. We classify this case as being colonized, but a beginning pneumonia cannot be excluded

${ }^{\mathrm{j}}$ Case \#15 was first treated for pneumonia. TZP was given for 4 days and then switched to MEM for 10 days. The patient developed a UTI caused by ESBLproducing E. cloacae complex 2 weeks after MEM had been stopped, for which a course of nitrofurantoin was given

${ }^{\mathrm{k}}$ The pneumonia and sepsis in case \#17 were treated with MEM. This intravenous therapy was switched to oral moxifloxacin after 10 days, as prolonged treatment was needed for streptococcal endocarditis. Two superficial sternal wounds were primarily treated with local wound care, but the ESBL-producing E. cloacae complex in these wounds may also have responded well to moxifloxacin

'Case \#18 was treated postoperatively with TZP and linezolid for aortic valve bioprosthesis endocarditis. The TZP treatment may have delayed the development of full-blown pneumonia

\section{Third outbreak episode}

A new cluster of six cases occurred in January 2018 (Fig. 1). All cases were adults, had undergone TEE examinations and had respiratory samples positive for ESBL-producing E. cloacae complex (Table 1). One case died from a non-infectious cause on the third postoperative day and probably did not have the time to develop pneumonia. The other five cases developed clinical infections and were treated with antibiotics. One patient died from ESBL-producing E. cloacae complex sepsis secondary to pneumonia.

Similar to the first outbreak episode, there was a minor increase in the incidence rate of ESBL-producing $E$. cloacae complex at SICU and MICU (Fig. 1). Two non-cardiac surgery patients could be identified who had undergone a TEE examination on the same day at MICU and who subsequently developed ESBL-producing E. cloacae complex pneumonia. One of these patients also developed a catheter-related bloodstream infection with ESBL-producing E. cloacae complex and died a few days later. Inspection of the TEE probe of CICU, which had been used in both patients, showed that a part of the silicone bead around the transducer lens was torn off (Fig. 2c). Measures taken to control the third outbreak episode included, among others, the obligatory use of a protective sheath to cover the TEE probe during cardiac surgery and the decision to switch from manual cleaning and disinfection using chlorine dioxide-generating wipes to automated reprocessing for the TEE probes of the operating rooms and CSICU (Fig. 3, Additional file 1: Table S1). The TEE probe of CICU and the TEE probe of the cardiology polyclinic, which also suffered from detachment of the silicone bead (Fig. 2d), were finally removed from service.

Only one new patient had positive cultures for ESBLproducing E. cloacae complex following cardiac surgery in the period from February 2018 to June 2018 (Fig. 1). As this was a single patient without a clear temporal or epidemiological relationship to the cases of January 2018, we did not consider this isolated finding as a new outbreak episode.

\section{Microbiological and molecular studies}

E. cloacae complex isolates of the first and second outbreak episode displayed a similar in vitro antibiotic resistance pattern, suggestive of SHV-like ESBL production (clavulanic acid-reversible resistance to third-generation cephalosporins, high-level resistance to trimethoprim- 

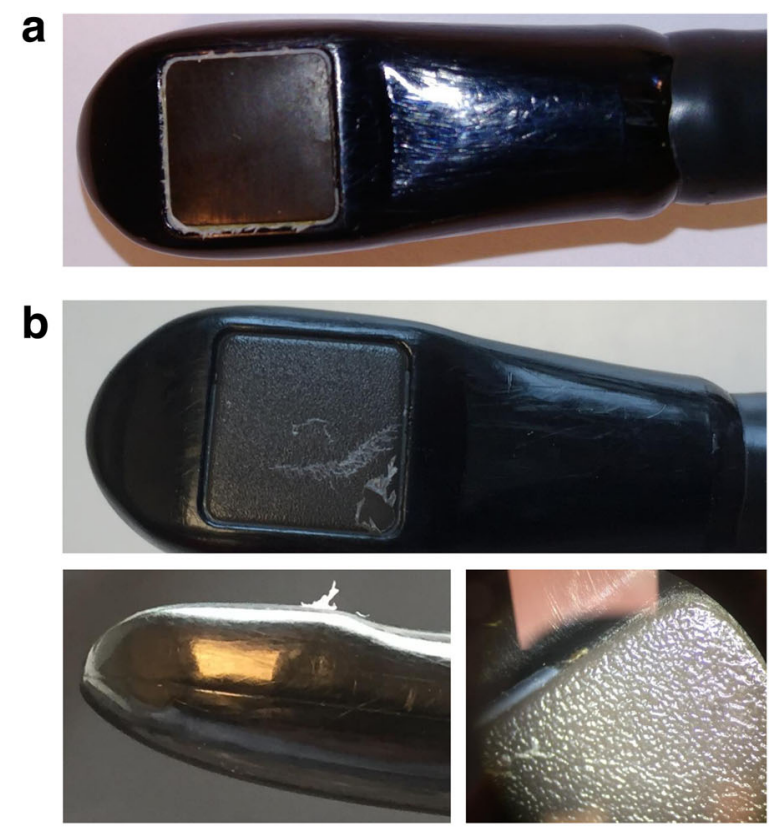

C

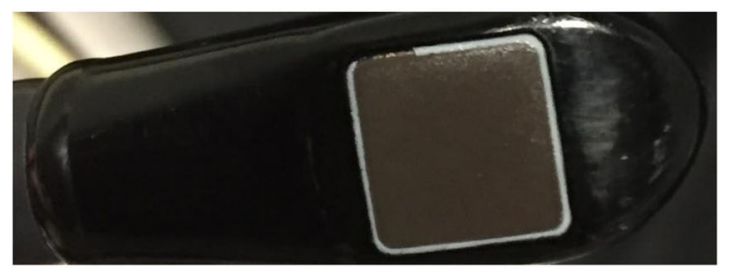

d

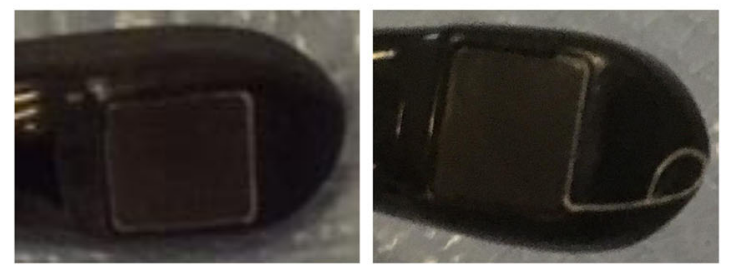

Fig. 2 Common pattern of damage of transesophageal echocardiography probes. All affected probes were of the same type (X7-2t transducer; Philips, Amsterdam, The Netherlands). a TEE probe of operating room A, beginning of July 2017. The silicone bead around the transducer lens was peeling off and was almost completely missing at one side (the side facing the shaft of the probe). This defect was accompanied by the complete absence of the protective polyethylene film that normally should cover the transducer lens. Shredded polyethylene film fragments can be seen along the remaining parts of the silicone seal. Orange discoloration of some ragged polyethylene film fragments and brown-yellow deposits in the area of the torn-off silicone bead cannot be seen on this picture, but were observed when the TEE probe was examined under a stereoscopic microscope (no pictures available) and were indicative of the presence of cellular debris and organic material. $\mathbf{b}$ TEE probe of CSICU, mid July 2017. A large part of the silicone bead was missing and the polyethylene film had partially come loose and was ruptured (top). The side view of the probe tip illustrates the detachment and rupture of the polyethylene film (bottom left). Yellow deposits can be seen in the area of the missing silicone bead (bottom right). c TEE probe of CICU, end of January 2018. A section of the silicone bead was missing. $\mathbf{d}$ TEE probe of the cardiology polyclinic, February 2018. The TEE probe appeared intact at the beginning of February 2018 (left), but a new inspection 3 weeks later revealed that a large part of the silicone bead had suddenly come off (right). Abbreviations: CICU cardiac intensive care unit, CSICU cardiac surgery intensive care unit, TEE transesophageal echocardiography

sulfamethoxazole and low-level resistance to ciprofloxacin and gentamicin). Isolates of the third outbreak episode showed a different antibiotic resistance profile (clavulanic acid-reversible resistance to third- and fourth-generation cephalosporins and high-level resistance to trimethoprim-sulfamethoxazole, ciprofloxacin and gentamicin). The high level of resistance to cefotaxime in the latter isolates suggested the production of a CTX-M-like ESBL.

Whole-genome sequencing was performed on isolates that had been collected from four cases of the first outbreak episode (cases 4, 6, 7 and 8), three cases of the second outbreak episode (cases 10, 11 and 12), four cases of the third outbreak episode (cases 14, 15, 16 and 18) and both non-cardiac surgery patients who had a similar TEE-associated infection and disease course in January 2018 as the case patients (PC1 and PC2). Three apparently unrelated ESBL-producing E. cloacae complex isolates, collected in October and November 2017 from non-cardiac surgery patients not involved in the outbreak (NC1, NC2 and NC3), were included as negative controls. Alignment of the contigs of the isolate genomes to the collection of $\beta$-lactam resistance genes in the ResFinder database [3,4] revealed an identical profile of $\beta$-lactam resistance genes for all isolates of the first and second outbreak episode (bla $a_{\mathrm{SHV}-12}$ with $100 \%$ identity and $b l a_{\mathrm{ACT}-15}$ with $>90 \%$ identity) and another identical profile for all isolates of the third outbreak episode and both isolates of patients PC1 and PC2 $\left(b l a_{\mathrm{CTX}-\mathrm{M}-15}, b l a_{\mathrm{TEM}-1 \mathrm{~B}}\right.$ and $b l a_{\mathrm{OXA}-1}$ with $100 \%$ 


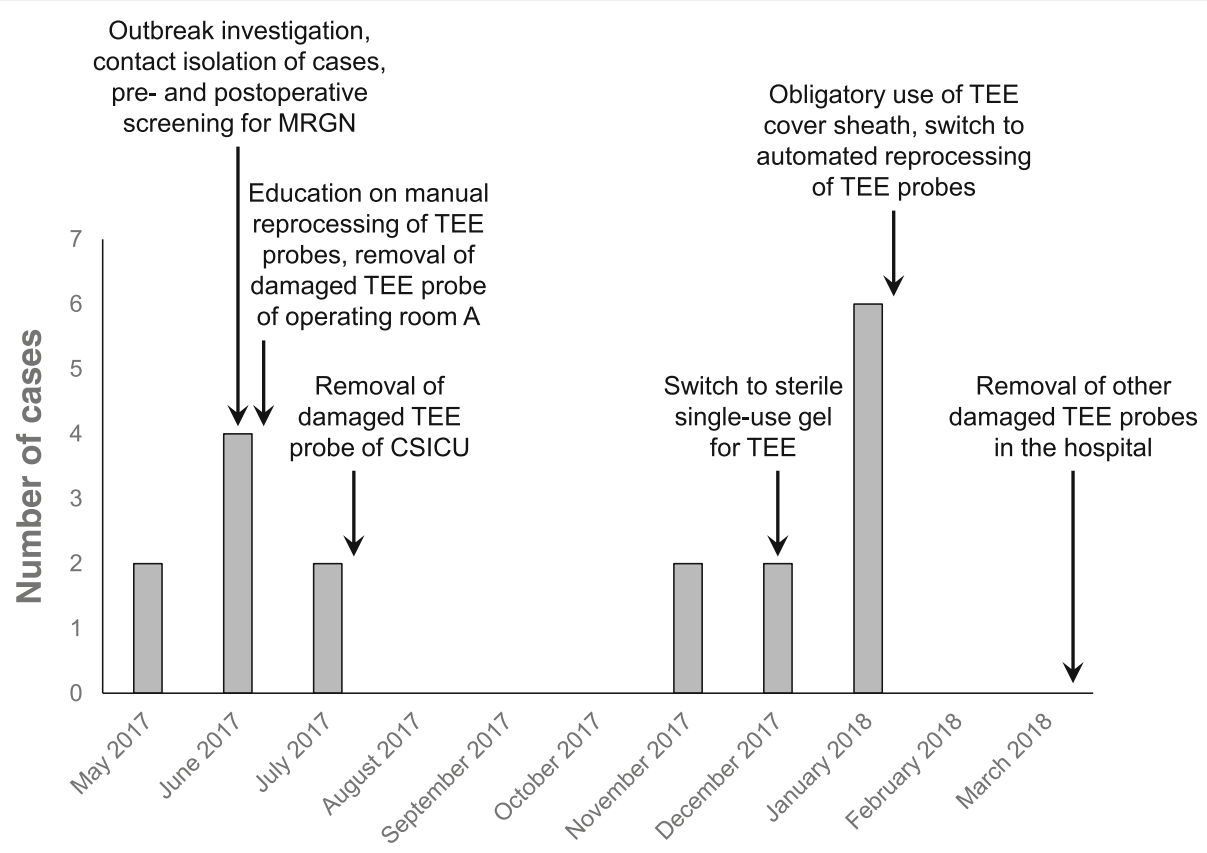

Fig. 3 Timeline of cases and key interventions performed to control the outbreak. A more detailed list of all infection control measures taken is shown in Additional file 1: Table S1. Abbreviations: CSICU cardiac surgery intensive care unit, MRGN multiresistant Gram-negative bacteria, TEE transesophageal echocardiography

identity and bla $a_{\mathrm{ACT}-16}$ with $>90 \%$ identity) (Fig. 4a). In contrast, ResFinder analysis did not detect the presence of any of these $\beta$-lactam resistance genes in the strains isolated from patients NC1, NC2 and NC3. Molecular typing using the MLST web tool of the Center for Genomic Epidemiology $[5,6]$ showed an identical sequence type for all isolates of the first and second outbreak episode (ST90), another common sequence type for all isolates of the third outbreak episode and those from patients PC1 and PC2 (ST114) and three different sequence types for the isolates derived from patients $\mathrm{NC1}, \mathrm{NC} 2$ and $\mathrm{NC} 3$ (ST729, ST104 and ST20, respectively) (Fig. 4b). Collectively, these findings strongly suggest that the first and second outbreak episode were caused by the same strain (SHV-12-producing E. cloacae complex ST90 clone), whereas a different strain was at the origin of the third outbreak episode (CTX-M-15-producing E. cloacae complex ST114 clone). The presence of an identical molecular pattern in the isolates cultured from patients $\mathrm{PC} 1$ and PC2 and the isolates from the case patients of the third outbreak episode adds further evidence to the hypothesis of TEE as mode of transmission, as the performance of a TEE examination was the only identifiable factor common to these two groups of affected patients.

A total of 82 environmental surveillance samples were collected for outbreak investigation, but none of them showed the presence of ESBL-producing E. cloacae complex. Periodic sampling of TEE probes, however, identified a transient contamination of the TEE probe of CSICU in
February 2018. Four different pathogens were cultured from a swab sample of the TEE probe that had been manually disinfected: ESBL-negative $E$. cloacae complex, Klebsiella oxytoca, Pseudomonas aeruginosa and Enterococcus faecalis (data not shown). A cardiac surgery patient was identified who had undergone a TEE examination with this probe $18 \mathrm{~h}$ before the sampling and who was known to have positive cultures for all four microorganisms, with highly similar antibiotic susceptibility patterns, pointing to the very likely point of origin of this contamination event. Careful monitoring of all microbiological laboratory results in the next 2 weeks did not provide evidence of cross-contamination to other patients.

\section{Discussion}

This article describes a protracted outbreak of postoperative infections with ESBL-producing E. cloacae complex in cardiac surgery patients, consisting of three episodes and involving two different bacterial strains. Previously published outbreaks of E. cloacae infections following cardiac surgery have been linked to surgical complications and cephalosporin prophylaxis [7], liberal use of cephalosporins [8], contamination of an intra-arterial monitoring device [9], contaminated cardioplegia ice [10] and increased use of cefepime and quinolones [11]. There is also one report of a TEE-associated increased incidence of $E$. cloacae isolated from oropharyngeal and sputum samples at a cardiovascular ward, without an accompanying increase in E. cloacae pneumonia [12]. We 
Table 2 Comparison of preoperative, intraoperative and postoperative characteristics between cases of the first outbreak episode and control patients

\begin{tabular}{|c|c|c|c|c|}
\hline Categorical variables & Case patients, $n$ (\%) & Control patients, $n(\%)$ & Odds ratio $(95 \% \mathrm{Cl})$ & $P$ value \\
\hline Female sex & $4(50)$ & $2(13)$ & $7.00(0.92-53.23)$ & .129 \\
\hline Smoker ${ }^{a}$ & $3(38)$ & $2(13)$ & $4.20(0.54-32.96)$ & .289 \\
\hline \multicolumn{5}{|l|}{ Medical history } \\
\hline Congestive heart failure & $4(50)$ & $5(31)$ & $2.20(0.39-12.57)$ & .412 \\
\hline Hypertension & $7(88)$ & $7(44)$ & $9.00(0.89-91.26)$ & .079 \\
\hline Myocardial infarction & $2(25)$ & $2(13)$ & $2.33(0.26-20.66)$ & .578 \\
\hline Peripheral vascular disease & $1(13)$ & $2(13)$ & $1.00(0.08-13.02)$ & 1.000 \\
\hline Cerebrovascular disease & $1(13)$ & $3(19)$ & $0.62(0.05-7.12)$ & 1.000 \\
\hline COPD & $1(13)$ & $3(19)$ & $0.62(0.05-7.12)$ & 1.000 \\
\hline Diabetes & $0(0)$ & $4(25)$ & $0.29(0.03-2.91)$ & .262 \\
\hline Chronic renal failure & $2(25)$ & $4(25)$ & $1.00(0.14-7.10)$ & 1.000 \\
\hline Dialysis & $1(13)$ & $0(0)$ & $4.25(0.33-54.07)$ & .333 \\
\hline Cirrhosis & $1(13)$ & $1(6)$ & $2.14(0.12-39.47)$ & 1.000 \\
\hline Solid organ transplantation & $0(0)$ & $1(6)$ & $0.89(0.07-11.22)$ & 1.000 \\
\hline Previous cardiac surgery & $0(0)$ & $1(6)$ & $0.89(0.07-11.22)$ & 1.000 \\
\hline \multicolumn{5}{|l|}{ Preoperative ICUs or wards ${ }^{b}$} \\
\hline CSICU & $2(25)$ & $1(6)$ & $5.00(0.38-66.01)$ & .249 \\
\hline $\mathrm{CICU}$ & $1(13)$ & $5(31)$ & $0.31(0.03-3.29)$ & .621 \\
\hline MICU & $0(0)$ & $1(6)$ & $0.89(0.07-11.22)$ & 1.000 \\
\hline SICU & $1(13)$ & $0(0)$ & $4.25(0.33-54.07)$ & .333 \\
\hline Cardiac surgery ward & $3(38)$ & $10(63)$ & $0.36(0.06-2.08)$ & .390 \\
\hline Cardiology ward & $2(25)$ & $3(19)$ & $1.44(0.19-11.04)$ & 1.000 \\
\hline Gastroenterology ward & $1(13)$ & $0(0)$ & $4.25(0.33-54.07)$ & .333 \\
\hline General internal medicine ward & $0(0)$ & $1(6)$ & $0.89(0.07-11.22)$ & 1.000 \\
\hline Geriatric ward & $1(13)$ & $0(0)$ & $4.25(0.33-54.07)$ & .333 \\
\hline Nephrology ward & $1(13)$ & $0(0)$ & $4.25(0.33-54.07)$ & .333 \\
\hline \multicolumn{5}{|l|}{ 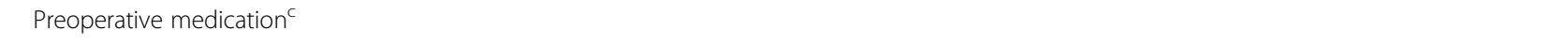 } \\
\hline Antibiotics $^{d}$ & $2(25)$ & $4(25)$ & $1.00(0.14-7.10)$ & 1.000 \\
\hline Proton pump inhibitors & $5(63)$ & $4(25)$ & $5.00(0.81-31.00)$ & .099 \\
\hline Systemic corticosteroids & $1(13)$ & $1(6)$ & $2.14(0.12-39.47)$ & 1.000 \\
\hline Preoperative ASA score of 5 & $4(50)$ & $0(0)$ & $17.00(1.59-181.36)$ & .007 \\
\hline \multicolumn{5}{|l|}{ Type of cardiac surgery } \\
\hline Aortic dissection repair & $2(25)$ & $0(0)$ & $7.29(0.64-82.62)$ & .101 \\
\hline Atrial surgery ${ }^{e}$ & $1(13)$ & $4(25)$ & $0.43(0.04-4.64)$ & .631 \\
\hline$C A B G^{f}$ & $2(25)$ & $6(38)$ & $0.56(0.08-3.69)$ & .667 \\
\hline Heart transplantation & $0(0)$ & $1(6)$ & $0.89(0.07-11.22)$ & 1.000 \\
\hline LVAD implantation $^{f}$ & $2(25)$ & $0(0)$ & $7.29(0.64-82.62)$ & .101 \\
\hline Valve repair or replacement $^{f}$ & $4(50)$ & $10(63)$ & $0.60(0.11-3.34)$ & .673 \\
\hline Emergency operation & $4(50)$ & $0(0)$ & $17.00(1.59-181.36)$ & .007 \\
\hline \multicolumn{5}{|l|}{ Operating room } \\
\hline Operating room A & $6(75)$ & $9(56)$ & $2.33(0.36-15.30)$ & .657 \\
\hline Operating room B & $1(13)$ & $7(44)$ & $0.18(0.02-1.86)$ & .189 \\
\hline Operating room $\mathrm{C}$ & $1(13)$ & $0(0)$ & $4.25(0.33-54.07)$ & .333 \\
\hline
\end{tabular}


Table 2 Comparison of preoperative, intraoperative and postoperative characteristics between cases of the first outbreak episode and control patients (Continued)

\begin{tabular}{|c|c|c|c|c|}
\hline \multicolumn{5}{|l|}{ Surgeons } \\
\hline Surgeon A & $4(50)$ & $8(50)$ & $1.00(0.18-5.46)$ & 1.000 \\
\hline Surgeon B & $4(50)$ & $6(38)$ & $1.67(0.30-9.27)$ & .673 \\
\hline Surgeon C & $4(50)$ & $5(31)$ & $2.20(0.39-12.57)$ & .412 \\
\hline Surgeon D & $2(25)$ & $8(50)$ & $0.33(0.05-2.18)$ & .388 \\
\hline Surgeon E & $2(25)$ & $6(38)$ & $0.56(0.08-3.69)$ & .667 \\
\hline Surgeon F & $2(25)$ & $0(0)$ & $7.29(0.64-82.62)$ & .101 \\
\hline Surgeon G & $1(13)$ & $0(0)$ & $4.25(0.33-54.07)$ & .333 \\
\hline Surgeon $\mathrm{H}$ & $1(13)$ & $0(0)$ & $4.25(0.33-54.07)$ & .333 \\
\hline Surgeon I & $1(13)$ & $0(0)$ & $4.25(0.33-54.07)$ & .333 \\
\hline Surgeon J & $0(0)$ & $4(25)$ & $0.29(0.03-2.91)$ & .262 \\
\hline Surgeon K & $0(0)$ & $1(6)$ & $0.89(0.07-11.22)$ & 1.000 \\
\hline \multicolumn{5}{|l|}{ Anesthesiologists } \\
\hline Anesthesiologist A & $5(63)$ & $7(44)$ & $2.14(0.38-12.20)$ & .667 \\
\hline Anesthesiologist B & $3(38)$ & $6(38)$ & $1.00(0.17-5.77)$ & 1.000 \\
\hline Anesthesiologist C & $2(25)$ & $6(38)$ & $0.56(0.08-3.69)$ & .667 \\
\hline Anesthesiologist D & $2(25)$ & $3(19)$ & $1.44(0.19-11.04)$ & 1.000 \\
\hline Anesthesiologist $\mathrm{E}$ & $2(25)$ & $1(6)$ & $5.00(0.38-66.01)$ & .249 \\
\hline Anesthesiologist F & $1(13)$ & $0(0)$ & $4.25(0.33-54.07)$ & .333 \\
\hline Anesthesiologist G & $1(13)$ & $0(0)$ & $4.25(0.33-54.07)$ & .333 \\
\hline Anesthesiologist $\mathrm{H}$ & $0(0)$ & $3(19)$ & $0.39(0.04-4.06)$ & .526 \\
\hline Anesthesiologist I & $0(0)$ & $1(6)$ & $0.89(0.07-11.22)$ & 1.000 \\
\hline Anesthesiologist J & $0(0)$ & $1(6)$ & $0.89(0.07-11.22)$ & 1.000 \\
\hline Anesthesiologist $\mathrm{K}$ & $0(0)$ & $1(6)$ & $0.89(0.07-11.22)$ & 1.000 \\
\hline Anesthesiologist L & $0(0)$ & $1(6)$ & $0.89(0.07-11.22)$ & 1.000 \\
\hline \multicolumn{5}{|l|}{ Surgical antibiotic prophylaxis } \\
\hline Cefazoline & $5(63)$ & $14(88)$ & $0.24(0.03-1.87)$ & .289 \\
\hline Vancomycin & $1(13)^{\mathrm{g}}$ & $0(0)$ & $4.25(0.33-54.07)$ & .333 \\
\hline Amoxicillin-clavulanic acid & $1(13)$ & $0(0)$ & $4.25(0.33-54.07)$ & .333 \\
\hline No additional coverage ${ }^{h}$ & $1(13)$ & $2(13)$ & $1.00(0.08-13.02)$ & 1.000 \\
\hline Sternotomy & $7(88)$ & $12(75)$ & $2.33(0.22-25.25)$ & .631 \\
\hline ECC & $8(100)$ & $16(100)$ & $-i$ & $-i$ \\
\hline Intraoperative TEE & $8(100)$ & $16(100)$ & $-i$ & $-i$ \\
\hline Postoperative $\mathrm{TEE}^{\mathrm{j}}$ & $7(88)$ & $5(31)$ & $15.40(1.47-160.97)$ & .027 \\
\hline Need for revision ${ }^{k}$ & $5(63)^{\prime}$ & $0(0)$ & $25.50(2.36-275.74)$ & .001 \\
\hline \multicolumn{5}{|l|}{ Beds occupied at CSICUm } \\
\hline Bed A & $1(13)$ & $4(25)$ & $0.43(0.04-4.64)$ & .631 \\
\hline Bed B & $1(13)$ & $3(19)$ & $0.62(0.05-7.12)$ & 1.000 \\
\hline Bed C & $0(0)$ & $3(19)$ & $0.39(0.04-4.06)$ & .526 \\
\hline Bed D & $1(13)$ & $3(19)$ & $0.62(0.05-7.12)$ & 1.000 \\
\hline Bed $\mathrm{E}$ & $4(50)$ & $1(6)$ & $15.00(1.29-174.39)$ & .028 \\
\hline Bed $F$ & $2(25)$ & $0(0)$ & $7.29(0.64-82.62)$ & .101 \\
\hline Bed G & $2(25)$ & $1(6)$ & $5.00(0.38-66.01)$ & .249 \\
\hline Bed $\mathrm{H}$ & $1(13)$ & $1(6)$ & $2.14(0.12-39.47)$ & 1.000 \\
\hline
\end{tabular}


Table 2 Comparison of preoperative, intraoperative and postoperative characteristics between cases of the first outbreak episode and control patients (Continued)

\begin{tabular}{|c|c|c|c|c|}
\hline Bed I & $1(13)$ & $2(13)$ & $1.00(0.08-13.02)$ & 1.000 \\
\hline Bed $J$ & $0(0)$ & $4(25)$ & $0.29(0.03-2.91)$ & .262 \\
\hline Death $^{n}$ & $2(25)$ & $1(6)$ & $5.00(0.38-66.01)$ & .249 \\
\hline Continuous variables & \multicolumn{2}{|c|}{ Case patients, median (IQR) } & Control patients, median (IQR) & $P$ value \\
\hline Age (yrs) & \multicolumn{2}{|c|}{$74(54-80)$} & $67(55-77)$ & .610 \\
\hline BMI $\left(\mathrm{kg} / \mathrm{m}^{2}\right)$ & \multicolumn{2}{|c|}{$26.5(24.7-31.0)$} & $26.2(24.0-28.2)$ & .492 \\
\hline Preoperative length of stay (days) & \multicolumn{2}{|c|}{$2(0-5)$} & $2(1-8)$ & .490 \\
\hline Duration of surgery (minutes) & \multicolumn{2}{|c|}{$275(221-394)$} & $197(158-223)$ & .011 \\
\hline Duration of ECC (minutes) & \multicolumn{2}{|c|}{$116(99-356)$} & $106(79-145)$ & .198 \\
\hline Length of stay at CSICU (days) & \multicolumn{2}{|c|}{$15(6-31)$} & $3(1-5)$ & .006 \\
\hline Postoperative length of stay (days) & \multicolumn{2}{|c|}{$30(26-39)$} & $10(7-13)$ & $<.001$ \\
\hline Total length of stay (days) & \multicolumn{2}{|c|}{$34(26-63)$} & $12(8-25)$ & .001 \\
\hline
\end{tabular}

Abbreviations: ASA American Society of Anesthesiologists, $B M I$ body mass index, $C A B G$ coronary artery bypass grafting, $C l$ confidence interval, $C I C U$ cardiac intensive care unit, COPD chronic obstructive pulmonary disease, CSICU cardiac surgery intensive care unit, ECC extracorporeal circulation, ESBL extended-spectrum $\beta$-lactamase, ICU intensive care unit, IQR interquartile range, LVAD left ventricular assist device, MICU medical intensive care unit, SD standard deviation, SICU surgical intensive care unit, TEE transesophageal echocardiography

${ }^{a}$ Current smoker. Findings were similar when smoking history was analyzed (data not shown)

b Intensive care units or wards where the patient was hospitalized prior to cardiac surgery

'Recent medication use (within seven days of cardiac surgery)

dPreoperative use of antibiotics for therapeutic purposes (infection). See below for perioperative antibiotic prophylaxis

${ }^{\mathrm{e}}$ One or more of the following procedures: left atrial appendage exclusion, maze procedure, patent foramen ovale closure. Atrial surgery was always performed in conjunction with another cardiac surgical procedure

${ }^{\mathrm{f}}$ Alone or in combination with another cardiac surgical procedure

gVancomycin was administered prophylactically to one patient who was already on treatment with piperacillin-tazobactam

${ }^{\mathrm{h}}$ No additional prophylactic use of antibiotics in patients already on antibiotic treatment

'Measures of association were not computed for categorical variables that had a constant value in each of the cases and controls

${ }^{j}$ Traceable TEE examination in the postoperative period. This may be an underestimation of the actual number of patients who had postoperative TEE examinations due to underregistration

${ }^{k}$ Postoperative need for urgent reoperation because of a major non-infectious complication

'Four patients required one or more revision operations for bleeding with imminent or manifest pericardial tamponade. Five of these revision operations occurred prior to infection with ESBL-producing E. cloacae complex (see Table 1). A fifth patient was reoperated because of postoperative mitral regurgitation with

hemodynamic instability. This revision took place shortly after the onset of infection with ESBL-producing E. cloacae complex

$\mathrm{m}_{\mathrm{Beds}}$ where the patient stayed at CSICU

${ }^{\mathrm{n}}$ Fatal outcome (overall mortality)

present multiple lines of evidence that point to TEE as the source of the current outbreak, including the clinical presentation of the cases (most typically with respiratory samples positive for ESBL-producing E. cloacae complex and development of pneumonia shortly after cardiac surgery), the resolution of the first and third outbreak episode after removal of the damaged TEE probes and institution of other TEE-directed infection control measures, the association of cases with longer surgery duration and traceable postoperative TEE examinations, the occurrence of similar infections in SICU and MICU patients who had undergone TEE and the detection of an identical molecular pattern between the isolates collected from the cases in January 2018 and those from two affected MICU patients, who appeared to have only TEE as common exposure factor. We did not detect ESBL-producing E. cloacae complex in any of the samples taken from the TEE probes, but a transient contamination of the TEE probe of CSICU with four other microorganisms was identified. The outbreak seemed to be primarily confined to ESBL-producing E. cloacae complex, as is illustrated in Additional file 1: Figure S1 and as is possibly in keeping with the absence of spreading to other patients when the transient contamination event with four other pathogenic bacteria occurred. The reasons for this species and subtype specificity are unclear, but may involve an increased susceptibility of cardiac surgery patients to Enterobacter infections [13] and a higher virulence of bacteria carrying antibiotic resistance-encoding plasmids [14]. It is striking that the epidemic returned with a different clone of ESBL-producing $E$. cloacae complex in January 2018. Of note, a highly similar TEEassociated outbreak of ESBL-producing E. cloacae complex in cardiac surgery patients occurred in 2015 and 2016 in another university hospital in Belgium [15]. With regard to the interval of 4 months between the first and second outbreak episode, which were caused by the same clone, possible explanations are reintroduction of the strain by a patient or untreated carrier or the presence of an environmental reservoir. Moist surfaces have been described as sources of ESBL-producing Enterobacteriaceae in the ICU, providing an opportunity for both outbreak 


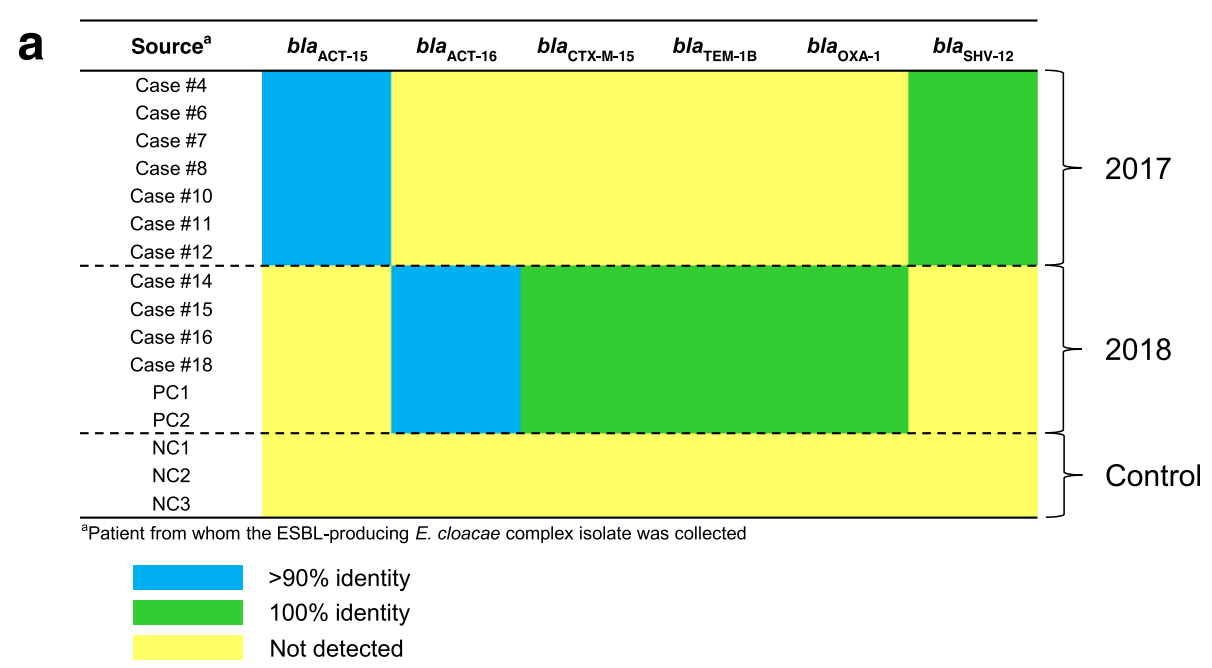

b

\begin{tabular}{|c|c|c|c|c|c|c|c|c|c|}
\hline Source ${ }^{a}$ & ST & $d n a A$ & fusA & gyrB & leus & pyrG & $r p / B$ & $r p o B$ & \\
\hline Case \#4 & 90 & 58 & 37 & 4 & 6 & 42 & 4 & 25 & \\
\hline Case \#6 & 90 & 58 & 37 & 4 & 6 & 42 & 4 & 25 & \\
\hline Case \#7 & 90 & 58 & 37 & 4 & 6 & 42 & 4 & 25 & \\
\hline Case \#8 & 90 & 58 & 37 & 4 & 6 & 42 & 4 & 25 & 2017 \\
\hline Case \#10 & 90 & 58 & 37 & 4 & 6 & 42 & 4 & 25 & \\
\hline Case \#11 & 90 & 58 & 37 & 4 & 6 & 42 & 4 & 25 & \\
\hline Case \#12 & _.90_. & - $\underline{5}$ & _ 37 _ & 4 & -6. & -42 & -4 & -25 & \\
\hline Case \#14 & 114 & 53 & 35 & 20 & 44 & 45 & 4 & 6 & \\
\hline Case \#15 & 114 & 53 & 35 & 20 & 44 & 45 & 4 & 6 & \\
\hline Case \#16 & 114 & 53 & 35 & 20 & 44 & 45 & 4 & 6 & 2018 \\
\hline Case \#18 & 114 & 53 & 35 & 20 & 44 & 45 & 4 & 6 & 2010 \\
\hline PC1 & 114 & 53 & 35 & 20 & 44 & 45 & 4 & 6 & \\
\hline$P C 2$ & 114 & 53 & -35 & $-2 \underline{0}$ & .44 & & & & \\
\hline $\mathrm{NC1}$ & 729 & 59 & 9 & 12 & 9 & 58 & 6 & 6 & \\
\hline $\mathrm{NC2}$ & 104 & 59 & 40 & 76 & 9 & 70 & 6 & 6 & Control \\
\hline $\mathrm{NC3}$ & 20 & 19 & 2 & 46 & 26 & 51 & 2 & 13 & \\
\hline
\end{tabular}

Fig. 4 Clonal relatedness of ESBL-producing E. cloacae complex isolates. a Profile of $\beta$-lactam resistance genes. Dashed lines separate the outbreak isolates of 2017 (first and second outbreak episode), the outbreak isolates of 2018 (third outbreak episode, supplemented with two isolates from non-cardiac surgery patients PC1 and PC2) and the negative control isolates (collected in 2017 from non-cardiac surgery patients not involved in the outbreak, denoted as NC1, NC2 and NC3). Blue, presence of a gene sequence in the isolate genome with $>90 \%$ identity to a $\beta$-lactam resistance gene in the ResFinder database; green, presence of a gene sequence in the isolate genome with $100 \%$ identity to a $\beta$-lactam resistance gene in the ResFinder database; yellow, resistance gene not detected in the isolate genome. $\mathbf{b}$ Sequence type as assessed by MLST. For each isolate genome, the best-matching allele at each locus of the MLST scheme was identified and sequence type was then determined by the combined allelic profile. Numbers shown are unique identifiers of alleles and sequence types. Dashed lines separate the outbreak isolates of 2017, the outbreak isolates of 2018 and the negative control isolates. Abbreviations: ESBL extended-spectrum $\beta$-lactamase, MLST multilocus sequence typing, ST sequence type

recurrence and continued sporadic isolation of the causative organism in the post-outbreak period [16].

A limitation of this investigation is that we were not able to assign specific TEE probes to cases on a one-by-one basis because of incomplete documentation and underregistration of TEE examinations. Prompt implementation of a system for full traceability was a major demand of the management board of the hospital when the third outbreak episode occurred. It should also be noted that not all cases can simply be attributed to a TEE procedure. For instance, case \#12 did not have a traceable TEE examination, suggesting the involvement of an alternative transmission route. Cross-contamination via the hands of healthcare workers is generally considered the main mode of transmission of ESBL-producing bacteria [17] and may perhaps account for a few cases of the reported outbreak.

We cannot be sure whether the TEE-mediated transmission events of ESBL-producing E. cloacae complex resulted from human errors in the manual reprocessing and handling of TEE probes or from an intrinsic failure of the cleaning and disinfection procedure. However, a striking observation was the similar pattern of damage of four different TEE probes. It seems highly plausible that irregular surfaces and poorly accessible nooks and crannies resulting from torn-off silicone parts and shredded polyethylene film fragments cannot be adequately disinfected anymore. An important question is what the root cause of this damage is. We have been cleaning and 
disinfecting the TEE probes manually using chlorine dioxide-generating wipes for several years, according to the manufacturer's recommendations. The same manual reprocessing method was in use in the other Belgian university hospital that suffered from a TEE-associated outbreak of ESBL-producing E. cloacae complex in cardiac surgery patients [15]. Chlorine dioxide is a strong oxidizing agent with broad-spectrum antimicrobial activity. Although the corrosive activity of chlorine dioxide is relatively low compared to other disinfectants [18], there are concerns that it may damage metal and polymer components of endoscopes [19], especially after long-term use [20]. It remains speculative whether the detachment of the silicone bead around the transducer lens and the rupture of the protective polyethylene film were caused by chlorine dioxide-induced corrosion. These defects could, e.g., also reflect a manufacturing problem or material weakness of the TEE probes, which was possibly aggravated by the repetitive mechanical action of wiping. In any case, a common underlying problem is very likely given the occurrence of the same type of damage with four individual devices. Much to our surprise, the compatibility testing report that can be requested from the manufacturer did not alleviate our concerns on a potential damaging effect of chlorine dioxidegenerating wipes and could serve as an additional relevant source of information to users of the same equipment. We finally made the decision to implement an automated reprocessing system for the TEE probes of the operating rooms and CSICU, which uses peracetic acid 5\% as highlevel disinfectant, and to impose the obligatory use of a TEE cover sheath during cardiac surgery.

\section{Conclusions}

In conclusion, this report documents a TEE-associated triphasic outbreak of postoperative infections with two distinct strains of ESBL-producing E. cloacae complex in cardiac surgery patients. Appropriate precautions must be taken to prevent and detect damage of TEE probes. The use of safe and effective reprocessing and handling methods is critical in this regard and regular inspection of TEE probe integrity is highly advisable.

\section{Supplementary information}

Supplementary information accompanies this paper at https://doi.org/10. 1186/s13756-019-0605-4.

Additional file 1: Table S1. Measures taken to control the outbreak of ESBL-producing E. cloacae complex in cardiac surgery patients. Figure $\mathbf{S 1}$. Monthly incidence rates of selected microorganisms at CSICU.

\section{Abbreviations}

AC: Arterial catheter; ASA: American Society of Anesthesiologists; ASD: Atrial septal defect; BAL: Bronchoalveolar lavage; BMI: Body mass index;

CABG: Coronary artery bypass grafting; Cl: Confidence interval; CICU: Cardiac intensive care unit; COPD: Chronic obstructive pulmonary disease;

CRBSI: Catheter-related bloodstream infection; CSICU: Cardiac surgery intensive care unit; CVC: Central venous catheter; ECC: Extracorporeal circulation; ESBL: Extended-spectrum $\beta$-lactamase; EUCAST: European Committee on Antimicrobial Susceptibility Testing; ICU: Intensive care unit; IQR: Interquartile range; LAA: Left atrial appendage; LVAD: Left ventricular assist device; MALDI-TOF MS: Matrix-assisted laser desorption/ionization timeof-flight mass spectrometry; MEM: Meropenem; MICU: Medical intensive care unit; MLST: Multilocus sequence typing; MRGN: Multiresistant Gram-negative bacteria; OR: Odds ratio; PFO: Patent foramen ovale; SD: Standard deviation; SICU: Surgical intensive care unit; ST: Sequence type; TEE: Transesophageal echocardiography; TZP: Piperacillin-tazobactam; UTI: Urinary tract infection; w/o: Without

\section{Acknowledgements}

We would like to thank the many clinicians and nurses who contributed to the investigation and containment of the outbreak. We gratefully acknowledge the lab technicians of the medical microbiology laboratory for their assistance.

\section{Authors' contributions}

TVM, JB and ILR conceptualized and designed the study. TVM, EDB, JB and ILR performed the outbreak investigation. EDB, PDW, RA, JB and ILR were responsible for conception and installation of the infection control measures. AN, PB and YG designed and supervised the molecular studies. LC, BV and JB designed and supervised the microbiological studies and evaluated the microbiological laboratory results for identifying cases. SB, IH and HP assisted with the outbreak investigation and were essential for successful

implementation of the outbreak control measures. TVM, AN, PB, BV, YG, JB and ILR analyzed and interpreted data. TVM drafted the manuscript. All authors read and critically reviewed the manuscript and approved the final version.

\section{Funding}

There was no funding for this study.

\section{Availability of data and materials}

All data generated or analysed during this study are included in this published article and its supplementary information file.

\section{Ethics approval and consent to participate}

The study was approved by the Medical Ethics Committee of Ghent University Hospital, which granted a consent waiver for reviewing the medical and laboratory records (reference number EC 2017/1279).

\section{Consent for publication}

Not applicable.

\section{Competing interests}

The authors declare that they have no competing interests.

\section{Author details}

'Department of Biomolecular Medicine, Ghent University, Ghent, Belgium. ${ }^{2}$ Department of Laboratory Medicine, AZ Groeninge, Kortrijk, Belgium. ${ }^{3}$ Department of Infection Control, Ghent University Hospital, Ghent, Belgium. ${ }^{4}$ Laboratory of Clinical Microbiology, Belgian National Reference Center for Monitoring Antimicrobial Resistance in Gram-Negative Bacteria, CHU UCL Namur, Yvoir, Belgium. ${ }^{5}$ Department of Laboratory Medicine, Ghent University Hospital, Ghent, Belgium. ${ }^{6}$ Department of Diagnostic Sciences, Ghent University, Ghent, Belgium. ${ }^{7}$ Department of Anesthesiology, Ghent University Hospital, Ghent, Belgium. ${ }^{8}$ Department of Intensive Care Medicine, Ghent University Hospital, Ghent, Belgium.

Received: 24 June 2019 Accepted: 4 September 2019

Published online: 18 September 2019

\section{References}

1. Mezzatesta ML, Gona F, Stefani S. Enterobacter cloacae complex: clinical impact and emerging antibiotic resistance. Future Microbiol. 2012;7:887-902.

2. Latour K, Yusuf E, Dodémont M, Glupczynski Y. Surveillance of antimicrobial resistant bacteria in Belgian hospitals: report 2016. Sciensano. 2018; https:// www.sciensano.be/sites/www.wiv-isp.be/files/rapport_amr_y2016 sciensano_final.pdf. Accessed 22 June 2019. 
3. ResFinder 3.0. https://cge.cbs.dtu.dk/services/ResFinder. Accessed 26 March 2018.

4. Zankari E, Hasman H, Cosentino S, Vestergaard M, Rasmussen S, Lund O, et al. Identification of acquired antimicrobial resistance genes. J Antimicrob Chemother. 2012;67:2640-4.

5. MLST 1.8 (Multi-Locus Sequence Typing). https://cge.cbs.dtu.dk/services/ MLST. Accessed 26 March 2018.

6. Larsen MV, Cosentino S, Rasmussen S, Friis C, Hasman H, Marvig RL, et al. Multilocus sequence typing of total-genome-sequenced bacteria. J Clin Microbiol. 2012;50:1355-61.

7. Palmer DL, Kuritsky JN, Lapham SC, King RM, AkI BF. Enterobacter mediastinitis following cardiac surgery. Infect Control. 1985;6:115-9.

8. Andersen BM, Sørlie D, Hotvedt R, Almdahl SM, Olafsen K, George R, et al. Multiply beta-lactam resistant Enterobacter cloacae infections linked to the environmental flora in a unit for cardiothoracic and vascular surgery. Scand J Infect Dis. 1989:21:181-91.

9. Thomas A, Lalitha MK, Jesudason MV, John S. Transducer related Enterobacter cloacae sepsis in post-operative cardiothoracic patients. J Hosp Infect. 1993;25:211-4.

10. Breathnach AS, Riley PA, Shad S, Jownally SM, Law R, Chin PC, et al. An outbreak of wound infection in cardiac surgery patients caused by Enterobacter cloacae arising from cardioplegia ice. J Hosp Infect. 2006;64:124-8.

11. Manzur A, Tubau F, Pujol M, Calatayud L, Dominguez MA, Peña C, et al. Nosocomial outbreak due to extended-spectrum-beta-lactamase-producing Enterobacter cloacae in a cardiothoracic intensive care unit. J Clin Microbiol. 2007:45:2365-9.

12. Kanemitsu K, Endo S, Oda K, Saito K, Kunishima H, Hatta M, et al. An increased incidence of Enterobacter cloacae in a cardiovascular ward. J Hosp Infect. 2007:66:130-4.

13. Flynn DM, Weinstein RA, Kabins SA. Infections with Gram-negative bacilli in a cardiac surgery intensive care unit: the relative role of enterobacter. J Hosp Infect. 1988;11(Suppl A):367-73.

14. Carattoli A. Plasmids and the spread of resistance. Int J Med Microbiol. 2013; 303:298-304.

15. Noël A, Vastrade C, Dupont $S$, de Barsy M, Huang TD, Van Maerken T, et al. Nosocomial outbreak of extended-spectrum $\beta$-lactamase-producing Enterobacter cloacae among cardiothoracic surgical patients: causes and consequences. J Hosp Infect. 2019:102:54-60.

16. Kac G, Podglajen I, Vaupré S, Colardelle N, Buu-Hoï A, Gutmann L. Molecular epidemiology of extended-spectrum beta-lactamase-producing Enterobacteriaceae isolated from environmental and clinical specimens in a cardiac surgery intensive care unit. Infect Control Hosp Epidemiol. 2004;25: $852-5$.

17. Paterson DL, Yu VL. Extended-spectrum $\beta$-lactamases: a call for improved detection and control. Clin Infect Dis. 1999;29:1419-22.

18. Wintner B, Contino A, O'Neill G. Chlorine dioxide, Part 1. A versatile, high-value sterilant for the biopharmaceutical industry. BioProcess Int. 2005;3:42-6.

19. Cleaning and disinfection of equipment for gastrointestinal endoscopy. Report of a Working Party of the British Society of Gastroenterology Endoscopy Committee. Gut. 1998;42:585-93. https://www.ncbi.nlm.nih.gov/ pubmed/9616326.

20. Coates D. An evaluation of the use of chlorine dioxide (Tristel one-shot) in an automated washer/disinfector (Medivator) fitted with a chlorine dioxide generator for decontamination of flexible endoscopes. J Hosp Infect. 2001; 48:55-65.

\section{Publisher's Note}

Springer Nature remains neutral with regard to jurisdictional claims in published maps and institutional affiliations.

Ready to submit your research? Choose BMC and benefit from:

- fast, convenient online submission

- thorough peer review by experienced researchers in your field

- rapid publication on acceptance

- support for research data, including large and complex data types

- gold Open Access which fosters wider collaboration and increased citations

- maximum visibility for your research: over $100 \mathrm{M}$ website views per year

At BMC, research is always in progress.

Learn more biomedcentral.com/submissions 